\title{
Rapid Orientation of Students for Emergency Remote Learning during the Covid-19 Lockdown
}

\author{
Danie de Klerk, ${ }^{\text {i }}$ Greig Krulli ${ }^{\text {ii }}$ Tshepiso Maleswena ${ }^{\text {iii }}$
}

\begin{abstract}
In response to the spread of the Covid-19 pandemic, the President of South Africa declared a national lockdown that commenced on 27 March 2020. This posed numerous challenges to the higher education sector, one of which was the preparation of students forced to stay at home to be able to study remotely under unique and often unfavourable circumstances. This article outlines and reflects on the conceptualisation, development, and implementation of an online orientation programme aimed at preparing students to rapidly move to emergency remote learning as a result of a nationwide lockdown. Teaching and Learning Centre staff in the Faculty of Commerce, Law and Management at a South African university rapidly created a short online orientation programme in the institutional Learning Management System, using Salmon's five-stage model as a conceptual framework. The objective was to enable students to acquire the skills and knowledge required for continuing with the university academic programme from 20 April 2020 via emergency remote learning. The orientation programme covered the priority areas of how to get started in emergency remote learning, broad study skills, how to use the required technologies for learning, and managing personal well-being during social isolation and emergency remote learning. In this article, the conceptualisation and development of the orientation programme is analysed, before reflecting on its implementation, challenges, mitigating measures, and lessons learned. Feedback from students indicates that the majority of students felt more prepared for continuing the academic programme, although they still reported feeling anxious about the many uncertainties. The intervention emerges as a useful strategy for helping students transition during a crisis and contributes to the understanding of how to prepare students for rapid transition to Emergency Remote Learning.
\end{abstract}

\section{Keywords}

Covid-19; emergency remote learning; orientation programme; student orientation; student success; student support

i Mr Danie de Klerk is Assistant Dean: Teaching and Learning, Teaching and Learning Centre, Faculty of Commerce, Law, and Management at the University of the Witwatersrand, South Africa.

ORCid: 0000-0001-8051-0833. Email: danie.deklerk@wits.ac.za

ii Dr Greig Krull is Director: Online Learning, Teaching and Learning Centre, Faculty of Commerce, Law, and Management at the University of the Witwatersrand, South Africa. ORCid: 0000-0002-0690-5869. Email: greig.krull@wits.ac.za

iii Ms Tshepiso Maleswena is Coordinator: Road to Success Programme, Teaching and Learning Centre, Faculty of Commerce, Law, and Management at the University of the Witwatersrand, South Africa. ORCid: 0000-0003-1182-9837. Email: tshepiso.maleswena@wits.ac.za 


\section{Introduction}

The South African Covid-19-related national lockdown meant that tertiary institutions had to rapidly move to a different mode of teaching and learning. Hodges, Moore, Lockee, Trust, and Bond (2020) refer to this shift as "Emergency Remote Teaching" (ERT), which they define as "a temporary shift of instructional delivery to an alternate delivery mode due to crisis circumstances" (para.13). The purpose of the shift to ERT is to provide quick access to teaching and support during the emergency. Emergency Remote Teaching and Learning (ERT\&L) is therefore different from the usual design and development of online learning programmes. Johnson, Veletsianos, and Seaman (2020) emphasise the importance of student support in the shift to ERT\&L classifying it as the "steps taken to support, care for, and enable students to succeed" (p. 16). Effective online learning takes place within a learning community where students are not just supported academically, but with other forms of support as well (Hodges et al., 2020). Thus, the need for the online student orientation to assist students to transition to Emergency Remote Learning (ERL) as illustrated by this article.

For student success and support entities, the shift to ERL meant orientating students from diverse backgrounds (i.e. different socio-economic contexts and levels of preparedness for tertiary studies) and (in some cases) remote locations for studying remotely during a global pandemic. Due to the unique conditions, there were no formal guidelines for how this orientation should be done, or what would be necessary to ensure that students are appropriately and adequately prepared for ERL. Nevertheless, the Academic Advisors and teaching and learning staff involved in the development of the online orientation programme, were able to draw on existing literature and a conceptual framework, survey data, and past experience to develop a suite of resources and activities aimed at rapidly preparing students for ERL. This was in part possible due to the existing policies and student support practices within the faculty (the Faculty of Commerce, Law, and Management or CLM) at the University of the Witwatersrand (Wits). Approximately 9000 registered students in the faculty were automatically enrolled in the orientation programme and 6131 students accessed at least some of the resources and activities during the orientation period (15 to 20 April 2020). The article highlights the context of the orientation programme within the institution and then reviews the current literature relevant to its approach and implementation. The conceptualisation and development of the orientation programme is then described, before reflecting critically on its implementation, challenges, mitigating measures, and lessons learned.

\section{Background and Context}

\section{Institutional framework to guide student success}

The Wits Institutional Framework for Student Success (WIFSS) (2019) forms the institutional backbone that guides Wits's approach to student success and support and places the student at the centre of the academic project. As such, it is intended to inform and guide the student success and support work done within faculties and elsewhere in 
the university. The purpose of the WIFSS (2019) is to strengthen the student success and support services on campus, strengthen the links between and amongst these services, and create a system of student support that students can navigate with greater ease. The WIFSS (2019) identifies four main areas of student support, namely (pp. 14-15):Academic Support, Health and Wellness, Material Needs, and Personal Development, all of which are addressed in annual orientation programmes (and elsewhere).

\section{Faculty approach to student success and support}

The CLM Teaching and Learning Centre houses, amongst other functions, the faculty's student success and support programme, known as the Road to Success Programme (RSP) (De Klerk, Spark, Jones \& Maleswena, 2017; Spark, De Klerk, Maleswena \& Jones, 2017). The RSP is directly involved in first-year student orientation and the institutional First Year Experience programme, annually. Four Academic Advisors and 16 peer advisors (known as Success Tutors) work in the unit to provide advisor support to students in the faculty (Spark et al., 2017). Since its inception in 2015 (De Klerk et al., 2017), the RSP has evolved to cover all four main areas of student support (including student orientation) identified in the WIFSS (2019), with all advisors either providing the required support to students or else referring them to specialists within the institution who can.

\section{Theoretical Framework}

For online students to be successful, they need to be supported through a structured development process. Salmon (2004) created the five-stage model as a framework for adopting a structured approach to online learning design in higher education, using constructivist pedagogic theory. The five stages of the model are: (i) access and motivation, (ii) online socialisation, (iii) information exchange, (iv) knowledge construction, and (v) development. The use of this model during the design process offers appropriate support to online students in each stage as they develop expertise in online learning (Salmon, 2004). Although there has been some critique of the model (Moule, 2007), it has been applied to support the design of online courses in different contexts (Johnson, 2017; Karaman \& Orhan Özen, 2016).

Given the need described earlier to rapidly design an orientation programme for students transitioning to ERL, the authors decided to focus on the first three stages of the five-stage model. The aim of Stage 1 (Access and motivation) is to provide a welcoming and encouraging introduction to the new learning environment, thus teaching students how to access the new learning environment and available technical support. The aim of Stage 2 (Online socialisation) is for students to become familiar with the online learning environment and the tools that are available. Students can start to interact with facilitators and other students by sending and receiving messages. The aim of Stage 3 (Information exchange) is for students to undertake various learning activities and make use of the available learning materials (Salmon, 2004). Once students had completed the online orientation programme, lecturers in individual courses would continue to provide scaffolded support for their students in this new learning environment. 


\section{Literature Review}

\section{Transition to emergency remote teaching and learning}

Much of the early literature examining the impact of Covid-19 on higher education has focused on the readiness of institutions, faculty experiences, and the support for staff to transition to a new way of teaching (see Bozkurt et al., 2020; Ferdig, Baumgartner, Hartshorne, Kaplan-Rakowski \& Mouza, 2020; Johnson et al., 2020). Very little of the initial literature has focused on the preparedness of students and how to assist students to transition to a new way of learning. However, several authors have raised concerns around inequities and differences in technological access for students (Adam, 2020; Bozkurt et al., 2020; Johnson et al., 2020). Adam (2020) notes that in addition to internet access, students require digital literacy and self-directed learning skills to benefit optimally from ERT. Bozkurt et al. (2020) highlight how the disruption has forced students to "regulate their own learning and become digitally savvy" (p. 3). The transition to ERT has required institutions to equip students with the necessary skills and resources to learn effectively in a remote setting.

The importance of support and care for students during the disruption has been considered by some studies. In a US survey of faculty and administrators, 58\% of staff reported needing assistance with information on how to best support students studying remotely (Johnson et al., 2020). Johnson et al. (2020, p. 17) suggest that institutions should ask the following question: "Are resources available to students to help them develop strategies for success in online learning environments?". Furthermore, these authors suggest that institutions undertake a needs assessment of students when transitioning during a crisis to determine whether they have access to the requisite technologies and to maintain awareness of socioemotional needs and inequities. To aid the transition of students during the disruption, some institutions have focused on the development of caring relations (Noddings, 2012) or the "pedagogy of care" (Bali, 2015) by listening to students and participating in open dialogue and then providing additional support to address their issues and challenges.

Due to the social isolation resulting from the pandemic, students appear to be suffering a great deal of anxiety, are dealing with issues of health and safety and are facing increasing financial pressures. This means that students would also require more emotional support than ever before and that institutions need to understand the social contexts in which their student live (Adam, 2020). Early student guidelines or reflections on the transition to ERL have highlighted the importance of setting up study routine schedules, to regularly engage with learning activities and to seek help when they have difficulties (academic or socio-emotional) (Bozkurt et al., 2020; COL, 2020). A transition to ERT\&L thus demands students are oriented to the skills and resources, study habits, and awareness of their needs befitting remote studies. Unsurprisingly, the Commonwealth of Learning's guidelines on distance education during Covid-19 therefore recommends educational institutions "provide orientation to students to effectively use online learning and to develop selfdirected learning skills by creating an engaging learning enrolment” (COL, 2020, p. 9). 


\section{Online student orientation}

As students transition from a face-to-face learning environment to an online environment, many are likely to feel anxious about their ability to succeed (Abdous, 2019). An orientation programme is commonly provided as a support mechanism for new university students to address expectations and requirements and to boost their preparedness (Abdous, 2019; Wozniak, Pizzica \& Mahony, 2012). Within online learning programmes, there are additional concerns around student success and student retention. Student orientation has been shown to have a positive impact on online student retention and success (Jones, 2013; Stone \& O’Shea, 2019). As many face-to-face institutions also began to offer online learning, they had to rethink and redesign their learner support services. This necessitated the establishment of orientation programmes that help prepare students and set expectations for their online learning experience (Farrell \& Brunton, 2020; Jones, 2013). An orientation programme also starts to build a community of students and provides direction and support for students who are encountering a new learning environment (Ludwig-Hardman \& Dunlap, 2003). Without proper induction to online learning, students may be unaware of what resources are available to help them or become challenged by the unfamiliarity of the Learning Management System (LMS) (Cho, 2012; Levy, 2006).

Several authors have proposed the objectives and topics to be contained in an online student orientation programme. Cho (2012) suggests four objectives for students: (i) to develop understanding about online learning, (ii) to use the LMS skilfully for learning, (iii) to solve any possible technical issues when using the LMS, and (iv) to develop selfawareness about the learning skills required to succeed. Bozarth, Chapman and LaMonica (2004) recommend that the topics in an orientation programme focus on "enhancing technological and self-management skills, while providing a realistic image of the online learning experience" (p. 89). Institutions also need to make decisions about whether to deliver the orientation online or in person, whether it is compulsory for all students to complete the programme (Harrell, 2008), and whether the orientation is self-paced or facilitated (Abdous, 2019). Another design consideration is the use of facilitators or moderators to encourage participation, assist those students who require help and respond to discussion posts (Wozniak et al., 2012). A benefit of an orientation course is that it provides a "risk-free playground" for students to become familiar with an online learning environment in a space that is not formally assessed (Wozniak et al., 2012). As learner needs are diverse, an orientation programme cannot address the needs of all students, but it does provide the means for students to know where to obtain further help. Wozniak et al. (2012) caution that an orientation course is not a once-off event as "students will tend to access resources as they are needed and may return to review them several times" during a semester (p. 908). This is confirmed by Douglas, Rogers and Ahuja (2018), who see an orientation as only the first part of a programme for supporting students during their firstyear experience. 


\section{CLM Student Orientation to Emergency Remote Learning}

\section{Rationale and conceptualisation}

The team involved in the conceptualisation, development, and implementation of the ERL orientation comprised Academic Advisors from the RSP, the CLM Assistant Dean for Teaching and Learning, and colleagues from the CLM Online Learning Team, all of whom work in the CLM Teaching and Learning Centre. It was acknowledged that students would have to be prepared for ERL, in the same way that mechanisms were being put in place to assist academics to transition to ERT. This would be achieved by creating a student orientation and support site in the Wits LMS, to which all CLM students would have access. Shortly after the lockdown commenced, CLM conducted an online survey of its students to gauge their technology and access needs during this period. Subsequently, survey results, coupled with information about concerns raised by students shortly after the national lockdown commenced, were used during the orientation programme development phase. This included students' apprehension about online learning, concerns about how the move to ERL might affect their performance, and uncertainty about their competence to participate in an unfamiliar mode of learning. Consequently, it was agreed that the orientation programme should introduce and orientate student to online learning (which would include how-to guides, videos, and other resources), provide low-stakes opportunities to model online assessment tools, and enable communication between students and advisors.

In order to collate their ideas, the team conducted a virtual brainstorming session using an online platform called Padlet where participants could populate and share ideas with each other. By drawing on previous interactions with students, the survey results, Salmon's (2004) five-stage model, and literature about ERT\&L and student orientation, advisors identified student needs in relation to ERL. Consequently, the team determined what type of resources needed to be developed (e.g. guidelines, infographics, videos, and activities) to achieve the desired objectives of the orientation programme. It was agreed that the orientation programme would be delivered through a platform that is easily accessible to all students (in alignment with the first stage of access and motivation of the five-stage model [Salmon, 2004]). Thus, the institutional LMS was selected as the platform for the orientation. The LMS had been zero-rated (i.e. little-to-no-data was being used when students and staff accessed the LMS) as a vital ERL resource with which many students were familiar (although this familiarity was limited, as not many had used the LMS for a full range of learning activities) and could be accessed from a variety of devices, including mobile devices. Furthermore, the issue of unpredictability meant that the orientation site had to be adaptable in order for minor changes and updates to be made throughout the period of ERT\&L. As such, delivering the orientation programme through the LMS could be of value to students not only during the orientation period, but for the remainder of the semester (and beyond ERL). 


\section{Aims and objectives of the orientation programme}

The first aim of the orientation programme was to develop resources and activities for equipping students with the requisite skills and abilities to learn remotely during the period of ERT\&L, thus aligning with the second stage (online socialisation) of Salmon's (2004) five-stage model. The programme had to provide advice and guidance for creating a home study environment conducive for learning from home, orientating parents/guardians/ family members to the demands of home study, assisting students with the development and implementation of revised time management plans and study techniques to accommodate the realities of ERL and Covid-19, and prepare them for online assessments (i.e. extended submission windows, taking quizzes through the LMS, and committing to honour pledges).

The second aim of the orientation programme was to develop a platform for communicating with students during lockdown and aligns with stage three (information exchange) of the five-stage model (Salmon, 2004). This would include explaining to students how to access student advisors within the faculty and provide information about other studentaffairs-related university support services. Regarding communication, although student correspondence occurred centrally through the Office of the Vice-Chancellor or the Dean of Students in most instances, there was faculty-specific information that had to be shared with students. Additionally, central messages with particularly important information, would be strategically reposted on the faculty student orientation site to ensure maximum exposure to the information. For students to contact faculty student advisors, the details and contact information for the advisors would be made available on the home page of the orientation site. The orientation site would also provide information on how to reach central university support services, such as the Wits Counselling and Careers Development Unit (CCDU) for booking online therapy sessions, contact details for the toll-free Wits Student Crisis Line (available 24/7 throughout the year to all registered Wits students), and information about the services offered by the Wits Gender Equity Office (GEO) during the ERT\&L period.

The third aim of the programme was to monitor student engagement with orientation activities to identify students who were, possibly, experiencing challenges with ERL. Academic Advisors would then be able to reach out to these students in an attempt to identify reasons for not engaging with the programme. It was anticipated that not all students registered on the orientation site would visit the site or participate in the orientation activities. This would apply particularly to postgraduate students enrolled for research degrees, those with connectivity and internet access challenges, those with inadequate devices or no device at all, and those who simply could not adapt to ERL. Nevertheless, analysing student engagement data daily during the orientation period would enable the team to identify, in particular, information about undergraduate students who might be struggling to access resources, which (together with reports from the institutional Business Intelligences Services) would enable Academic Advisors to contact students who were not actively accessing online resources in the LMS. 


\section{Orientation programme structure, sequencing, and pacing}

To achieve these aims and objectives, the team developed a four-day programme within the LMS. Each day was split into two parts (a morning and an afternoon session) with tasks, activities, and resources linked to each session. Once students navigated to the orientation site, they would come to a landing page where they were welcomed and introduced to the site and its objectives. On this landing page, students were able to view a three-minute orientation video that had been created using a free online resource called Biteable. With a focus on "low-tech" accessibility and to cater for students with connectivity issues as much as possible, all information contained in videos or podcasts was also made available in text format. The introductory message explained that there would be daily sessions for students to complete, with each day's activities launched on that day. This meant that students would be guided through the daily activities and they would have to come back the next day to access the next set of tasks and activities. The orientation programme was rolled out over a four-day period using this staggered approach. The team felt this would provide students with adequate time to engage with each component of the orientation programme and allow them to complete the relevant tasks and activities without overloading them with too much information. Students were given two additional days after the fourth day of the orientation programme, to submit the final assignment and complete the evaluation form. Further details about the activities and components of each day are provided in Table 1 below.

Table 1: Breakdown of activities and components of the ERL orientation programme

\begin{tabular}{|l|l|}
\hline Focus & Activities and Components \\
\hline Day 1: Getting Started & $\begin{array}{l}\text { 1. Watch orientation video and read welcome message } \\
\text { on site home page. }\end{array}$ \\
2. Take a poll about initial feelings towards ERL and \\
perceived preparedness for ERL.
\end{tabular}




\begin{tabular}{|c|c|}
\hline Focus & Activities and Components \\
\hline Day 2: Excellence Skills & $\begin{array}{l}\text { 1. Review Frequently Asked Questions section. } \\
\text { 2. Visit Faculty Information Portal for additional } \\
\text { information about ERL and Covid-19. } \\
\text { 3. Take a poll to gauge the suitability of home study } \\
\text { environments for ERL. } \\
\text { 4. Review guidelines about etiquette for engaging in } \\
\text { online spaces. } \\
\text { 5. Review infographic with ten tips for studying online. } \\
\text { 6. Review infographic with information for taking notes } \\
\text { when studying remotely. } \\
\text { 7. Read guidelines for managing time when studying } \\
\text { remotely. } \\
\text { 8. Draft a time management plan using the time } \\
\text { management template provided. } \\
\text { 9. Review the infographic for taking online assessments. } \\
\text { 10. Watch the How to Access E-Books video to be able to } \\
\text { access e-books from the library. }\end{array}$ \\
\hline Day 3: How-to Guides & $\begin{array}{l}\text { 1. Review updates about zero-rating on the Wits website. } \\
\text { 2. Watch the How to Navigate the LMS video. } \\
\text { 3. Take a poll to gauge level of comfort with using the } \\
\text { LMS for ERL. } \\
\text { 4. Watch the How to Use Turnitin video. } \\
\text { 5. Watch the video for How to Access a Microsoft Teams Live } \\
\text { Meeting. } \\
\text { 6. Read the guide on How to Use the Lesson Tool in } \\
\text { the LMS. } \\
\text { 7. Read the guide on How to Use the Chat Function in } \\
\text { the LMS. } \\
\text { 8. Read the guide on How to Take an Online Quiz in } \\
\text { the LMS. } \\
\text { 9. Take the online quiz to test your knowledge of online } \\
\text { learning and practice using the quiz tool. } \\
\text { 10. Optional activity: Complete the free Microsoft Digital } \\
\text { Literacy online course. }\end{array}$ \\
\hline Day 4: Personal Well-being & $\begin{array}{l}\text { 1. Review updates about zero-rating on the Wits website. } \\
\text { 2. Watch the video on Mental and Emotional Wellbeing } \\
\text { During Social Isolation and/or review the accompanying } \\
\text { infographic. } \\
\text { 3. Review the CCDU Lockdown Wellness Chronicles on } \\
\text { the Wits website and view the poster about Cyber } \\
\text { Bullying from CCDU. } \\
\text { 4. Take note of the Wits Student Crisis Line contact } \\
\text { details. }\end{array}$ \\
\hline
\end{tabular}




\begin{tabular}{|c|c|}
\hline Focus & Activities and Components \\
\hline $\begin{array}{l}\text { Day 4: Personal Well-being } \\
\text { (continued) }\end{array}$ & $\begin{array}{l}\text { 5. Review the South African Social Sector Directory of } \\
\text { Services Contact Particulars document with information } \\
\text { about national contact centres and services during } \\
\text { Covid-19. } \\
\text { 6. Learn about Covid-19 by reading the infographic } \\
\text { about Covid-19. } \\
\text { 7. Review the infographic about keeping your hands } \\
\text { clean to help prevent the spread of Covid-19. } \\
\text { 8. Complete the Online Orientation evaluation form. } \\
\text { 9. Watch the final assignment instruction video and do } \\
\text { the assignment. }\end{array}$ \\
\hline
\end{tabular}

\section{Methodology}

The authors adopted a Design-Based Research (DBR) methodology, which is commonly used within the learning sciences, and involves the development of a context-based solution or intervention in response to a particular educational problem (Anderson \& Shattuck, 2012). The approach would typically see researchers analyse interventions iteratively (i.e. design, review, and iterate), but owing to a lack of time and scope during the Covid-19 emergency, an exhaustive iterative approach was not possible. Nevertheless, DBR is used to address real-life issues in education, like rapidly orientating students to ERL, and entails the collection of data in multiple ways, which is what the authors did for this study. The intention is to use this orientation programme and the lessons learned from it as a baseline for subsequent online orientation programmes, such as those for incoming first-year students.

Data collection occurred in a number of ways over the course of the four-day orientation programme. Student engagement was tracked daily and at the end of the four-day period via the LMS Statistics tool. For the purposes of this article, only highlevel user access and engagement data will be analysed (i.e. the number of individual student visits for the four-day period and the number of clicks per user), although it would be possible to drill down further on activity and assessment data if required. Students' preparedness, perceptions, and level of comfort was gauged using the LMS Polls tool and this data will be analysed for this study. Additionally, final-assignment-submission data from the Assignment tool was analysed and will also be shared in the Findings and Discussion section below. Finally, student evaluation data, collected at the end of the orientation programme using an online survey created in LimeSurvey, was analysed to gauge students' perceived readiness for ERL, their level of comfort with using online tools and resources, and to identify further support needs. An analysis of the aforementioned data is shared and discussed in the Findings and Discussion section below. 


\section{Findings and Discussion}

\section{Figures and statistics}

Prior to the launch of the ERL orientation programme, 9088 registered CLM students (of which 4937 were undergraduate and 4151 postgraduate) were added to the LMS orientation site. An announcement was posted on the site to inform all students about the orientation programme that would launch the following day. The team knew that not all students would participate in the orientation activities (in particular those enrolled for fullresearch degrees and some of the postgraduate programmes), which were not compulsory. Nevertheless, they wanted to make sure that the resources on the site were available to all CLM students. The orientation programme was launched on 15 April 2020 and concluded on 18 April 2020, although students were able to submit final tasks until 19 April 2020 and could complete evaluations until 20 April 2020. During the four-day period under review, 6131 individual students accessed the orientation site and although it is difficult to determine how many completed every component of the orientation programme, the team is satisfied with a $67 \%$ engagement rate over just four days.

Table 2 shows the result of the three daily polls administered on the first three days of the orientation programme. Poll 1 was completed by 4688 individual students and asked about students' preparedness for ERL and the prospects of online studies. Poll 2 was completed by 3899 individual students and aimed to assess the suitability of their home study environment for ERL. Finally, Poll 3 was completed by 3285 individual students and asked about their level of comfort with using the institutional LMS as an online learning platform.

Table 2: Daily poll results

\begin{tabular}{|l|l|}
\hline Poll Question & Results \\
\hline $\begin{array}{l}\text { Poll 1: How do you } \\
\text { feel about taking your } \\
\text { studies online? }\end{array}$ & $\begin{array}{l}\text { - } 2464 \text { respondents (53\%) felt nervous or extremely nervous } \\
\text { about ERL and taking their studies online. }\end{array}$ \\
& $\begin{array}{l}\text { - } 1695 \text { respondents (36\%) felt both nervous and excited } \\
\text { about the prospects of ERL. }\end{array}$ \\
\hline $\begin{array}{l}\text { Poll 2: What best } \\
\text { describes your home } \\
\text { study environment? }\end{array}$ & $\begin{array}{l}\text { - } 931 \text { respondents }(24 \%) \text { said their home study environment } \\
\text { was either not suitable or less than ideal for ERL. }\end{array}$ \\
& $\begin{array}{l}1513 \text { respondents (39\%) said they could make their home } \\
\text { study environments work in the current circumstances. }\end{array}$ \\
& $\begin{array}{l}1455 \text { respondents (37\%) deemed their home study } \\
\text { environment either suitable or ideal for ERL. }\end{array}$ \\
\hline
\end{tabular}




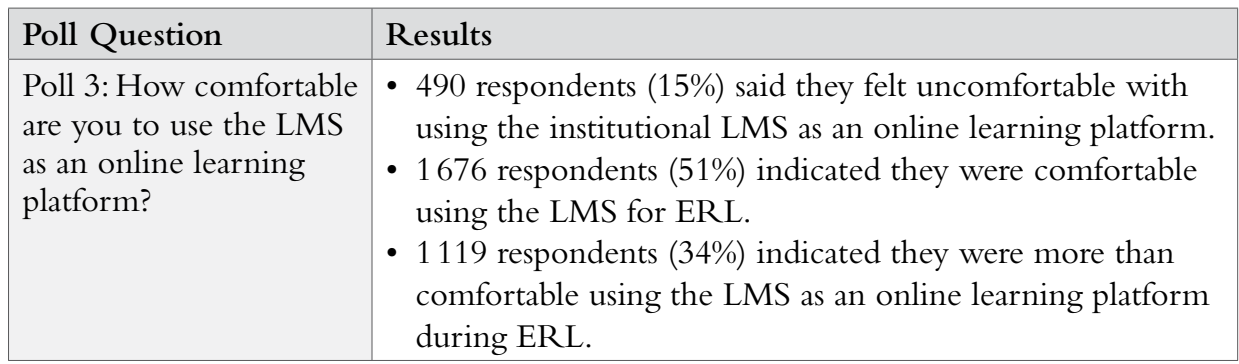

Six hundred and fifty-eight (658) individual students completed and submitted the richpicture final assignment, while 1113 individual students completed the online orientation evaluation. Assignment submissions were lower than expected, although not surprising considering that tasks were voluntary and that marks were not awarded (both factors anecdotally observed to influence students' decision to engage with learning activities). Evaluation results were resoundingly positive, with more than $80 \%$ of respondents finding the shared resources and information useful, indicating the orientation programme was worth their while, and expressing high levels of satisfaction about their ability to use online assessment and communication tools. However, the authors recognise the limitation of the study in that those students who completed the entire programme were likely those who found it most useful (thus reflecting a great deal of satisfaction in the survey). Another concern is that about $30 \%$ of the respondents indicated that they still felt apprehensive about taking their studies online and that they were uncertain about the unfamiliar learning environment they were entering.

\section{Discussion}

The development and rollout of the orientation programme presented more challenges than initially anticipated. The team had limited time in which to implement the various solutions that would achieve the desired outcomes, while having no formal guidelines on which to base the orientation programme for ERT\&L. To mitigate these challenges, the team drew on information gleaned from the online student survey conducted shortly after the lockdown commenced, Salmon's (2004) five-stage model, existing knowledge about online learning and orientation programmes (Abdous, 2019; Bozarth et al., 2004; Cho, 2012), the limited literature about ERT\&L that existed at the time, and established holistic student support principles to develop and implement the ERL orientation programme. Needless to say, this period was fraught for students as the orientation polls indicated that $53 \%$ of students were nervous or extremely nervous about ERL and $24 \%$ of students were living in home environments that were unconducive for ERL studies. Therefore, the development of this programme helped to address some student concerns and further highlight issues of accessibility and more general factors affecting learning. Furthermore, a "low-tech" approach (e.g. making available text versions of video or audio files, amongst other things) was adopted to reduce the challenges (where possible) for students with poor connectivity and limited data. 
A major concern was that some students could not access or did not benefit from this orientation programme during the orientation period. More than $20 \%$ of students enrolled on the site did not access the orientation programme during the orientation period, while only about one in six students completed the evaluation. In alignment with Douglas et al. (2018) and Wozniak et al. (2012), this was mitigated by keeping the site and resources active and accessible to students throughout the academic year. Academic Advisors and peer advisors continue to use the site to communicate and consult with students, while adding new resources when needed (e.g. guidelines for examination preparation and online examinations). Regarding the low survey response rate, although a $12 \%$ response rate to the orientation programme evaluation is less than ideal, one should bear in mind that none of the activities were compulsory, and that survey fatigue may have contributed to the low response rate. The lessons learned from the development of this online orientation programme can be applied in the development of similar programmes for online learning in the institution and the development of support mechanisms to assist students during any future periods of disruption.

\section{Conclusions}

Due to the rapid transition to ERL, an online orientation programme was quickly conceptualised and developed to support students in the Faculty of Commerce, Law, and Management to make this transition. This conceptualisation was based upon Salmon's (2004) five-stage model, a review of the literature, a student survey and the previous experiences of the orientation programme developers. The majority of students within CLM completed at least some of the activities during the orientation period and the students who responded to the evaluation mainly responded positively. The team is satisfied that the programme achieved its main objectives of introducing and orientating students to online learning, providing resources that helped students acquire knowledge and tools for ERL, providing how-to guidelines and videos for ERL, modelling the use of online assessment tools in a low-stakes environment, providing advice and guidance about personal well-being during social isolation and while studying remotely, and enabling communication between students and advisors via LMS communication tools and email. The approach to the development of this online orientation programme is offered as a contribution to the field to assist in the rapid development of online orientation programmes for any future periods of disruption to higher education. Additionally, the programme offered the team an opportunity to gain insight into the challenges students face, their needs during this period, and to identify students who were either ill-prepared for ERL or did not access the online orientation programme at all during the orientation period.

\section{Acknowledgements}

The authors would like to extend their sincere gratitude to the following individuals for their input, advice, guidance, and contribution: Prof. Jason Cohen, Dr Laura Dison, Ms Siyasamkela Jinoyi, Ms Fiona Macalister, Ms Aneshree Nayager, and Mr Mbongeni Shungube. 


\section{Research Ethics}

The authors subscribe to the highest levels of ethics during their research. Only secondary data was used in this study. All data is presented in aggregate form and no individual is identifiable from the data shared in this article.

\section{Conflict of Interest}

The authors have no conflict of interest to declare.

\section{Funding}

No funding was required to complete this study.

\section{References}

Abdous, M.H. (2019). Influence of satisfaction and preparedness on online students' feelings of anxiety. The Internet and Higher Education, 41,34-44. https://doi.org/10.1016/j.iheduc.2019.01.001

Adam, T. (2020). The privilege of \#pivotonline: A South African perspective. Open Education and Development. https://opendeved.net/2020/04/22/the-privilege-of-pivotonline/\#pivotonline/

Anderson, T. \& Shattuck, J. (2012). Design-Based Research:A Decade of Progress in Education Research? Educational Researcher, 41(1), 16-25. https://doi.org/10.3102/0013189X11428813

Bali, M. (2015). Pedagogy of Care - Gone Massive. Hybrid Pedagogy. https://hybridpedagogy.org/pedagogyof-care-gone-massive/

Bozarth, J., Chapman, D.D. \& LaMonica, L. (2004). Preparing for distance learning: Designing an online student orientation course. Educational Technology \& Society, 7(1), 87-106.

Bozkurt, A., Jung, I., Xiao, J.,Vladimirschi,V., Schuwer, R., Egorov, G., .. Paskevicius, M. (2020). A global outlook to the interruption of education due to Covid-19 Pandemic: Navigating in a time of uncertainty and crisis. Asian Journal of Distance Education, 15(1), 1-126. https://doi.org/10.5281/ zenodo. 3878572

Cho, M. (2012). Online student orientation in higher education: a developmental study. Educational Technology Research and Development 60(6), 1051-1069. https://doi.org/10.1007/s11423-012-9271-4

COL (2020). Guidelines on Distance Education during Covid-19. Canada: COL.

De Klerk, D., Spark, L., Jones, A. \& Maleswena, T. (2017). Paving the Road to Success: Reflecting critically on year one of an undergraduate student support programme at a large South African university. Journal of Student Affairs in Africa, 5(1),1-13. https://doi.org/10.24085/jsaa.v5i1.2478

Douglas, T., Rogers, M. \& Ahuja, K. (2018). Challenging the perceptions of orientation in higher education: Student perspectives of a transition initiative. In D. Wache \& D. Houston (Eds.), Research and Development in Higher Education: (Re)Valuing Higher Education, 41 (pp. 69-80). Adelaide, Australia, $2-5$ July.

Farrell, O. \& Brunton, J. (2020). A balancing act: A window into online student engagement experiences. International Journal of Educational Technology in Higher Education, 17(25). https://doi.org/10.1186/ s41239-020-00199-x

Ferdig, R.E., Baumgartner, E., Hartshorne, R., Kaplan-Rakowski, R. \& Mouza, C. (Eds). (2020). Teaching, Technology, and Teacher Education During the Covid-19 Pandemic: Stories from the Field. Association for the Advancement of Computing in Education (AACE).

Harrell, I.L. (2008). Increasing the success of online students. Inquiry, 13(1), 36-44.

Hodges, C., Moore, S., Lockee, B., Trust, T. \& Bond, A. (2020). The difference between emergency remote teaching and online learning. Educause Review. https://er.educause.edu/articles/2020/3/ the-difference-between-emergency- remote-teaching-and-online-learning 
Johnson, C.S. (2017). Collaborative technologies, higher order thinking and self-sufficient learning: A case study of adult learners. Research in Learning Technology, 25. https://doi.org/10.25304/rlt.v25.1981

Johnson, N., Veletsianos, G. \& Seaman, J. (2020). U.S. faculty and administrators' experiences and approaches in the early weeks of the Covid-19 pandemic. Online Learning, 24(2), 6-21. https://doi. org/10.24059/olj.v24i2.2285

Jones, K.R. (2013). Developing and implementing a mandatory online student orientation. Journal of Asynchronous Learning Networks, 17(1), 43-45. https://doi.org/10.24059/olj.v17i1.312

Karaman, M.K. \& Orhan Özen, S. (2016). A Survey of Students' Experiences on Collaborative Virtual Learning Activities Based on Five-Stage Model. Educational Technology \& Society, 19 (3), 247-259.

Levy, P. (2006). 'Living' theory: A pedagogical framework for the process support in networked learning. Research in Learning Technology, 14(3), 225-240. https://doi.org/10.1080/09687760600837025

Ludwig-Hardman, S. \& Dunlap, J.C. (2003). Learner support services for online students: Scaffolding for success. The International Review of Research in Open and Distributed Learning, 4(1), 1-15. https://doi. org/10.19173/irrodl.v4i1.131

Moule, P. (2007). Challenging the five-stage model for e-learning: a new approach. Research in Learning Technology, 15(1), 37-50. https://doi.org/10.1080/09687760601129588

Noddings, N. (2012). The caring relation in teaching. Oxford Review of Education, 38(6), 771-781. https:// doi.org/10.1080/03054985.2012.745047

Salmon, G. (2004) E-moderating: The key to online teaching and learning (2nd ed.). Routledge. https://doi. org/10.4324/9780203465424

Spark, L., De Klerk, D., Maleswena, T. \& Jones, A. (2017). Paving the Road to Success: A framework for implementing the Success Tutoring approach. Journal of Student Affairs in Africa, 5(2), 77-90. https://doi. org $/ 10.24085 /$ jsaa.v5i2.2703

Stone, C. \& O'Shea, S. (2019). Older, online and first: Recommendations for retention and success. Australasian Journal of Educational Technology, 35(1). https://doi.org/10.14742/ajet.3913

WIFFS (2019). Wits Institutional Framework for Student Success. University of the Witwatersrand: December.

Wozniak, H., Pizzica, J. \& Mahony, M.J. (2012). Design-based research principles for student orientation to online study: Capturing the lessons learnt. Australasian Journal of Educational Technology, 28(5), 896-911. https://doi.org/10.14742/ajet.823

\section{How to cite:}

De Klerk, D., Krull, G. \& Maleswena, T. (2021). Rapid Orientation of Students for Emergency Remote Learning during the Covid-19 Lockdown. Journal of Student Affairs in Africa, 9(1), 61-75. DOI: $10.24085 /$ jsaa.v9i1.1428 